\title{
BENEFÍCIOS DO SISTEMA START STOP NO CONSUMO DE COMBUSTÍVEL VEICULAR E EMISSÕES DE $\mathrm{CO}_{2}$ : REVISÃO DA LITERATURA
}

\author{
Rosiana da Silva Lopes ${ }^{1}$, Paulo César S. de Araújo ${ }^{2}$, Sandro Marcos Campos Soares ${ }^{2}$ e \\ Fabrício José Pacheco Pujatti ${ }^{1}$ \\ ${ }^{1}$ Universidade Federal de Minas Gerais - UFMG - Programa de Pós Graduação em \\ Engenharia Mecânica - PPGMEC \\ ${ }^{2}$ Fiat Chrysler Automobiles - FCA Latam \\ E-mails: rosianalopes16@gmail.com, paulo.araujo@fcagroup.com, \\ $\underline{\text { sandro.soares@fcagroup.com e pujatti@demec.ufmg.br }}$
}

\section{RESUMO}

Este trabalho apresenta uma revisão da literatura sobre os benefícios do sistema Start stop no consumo de combustível e emissões de $\mathrm{CO}_{2}$ de veículos automotivos. A frota de veículos lança constantemente para atmosfera gases poluentes e tóxicos além de ser um dos setores que mais consomem combustíveis de origem fóssil. Em razão disso o desenvolvimento tecnológico para reduzir as emissões de poluentes e o consumo de combustível se faz necessário para preservar o meio ambiente. O sistema Start stop foi desenvolvido para reduzir o consumo de combustível automotivo, por meio do desligamento do motor em períodos de parada do veículo em condições de trânsito, evitando desperdício de combustível. Este artigo tem o objetivo de revisar os benefícios do sistema Start stop no consumo de combustível e emissões de $\mathrm{CO}_{2}$. Os resultados mostram que o sistema pode reduzir o consumo de combustível em até $20 \%$ em tráfego urbano e outras versões do sistema podem gerar melhores resultados, o Start stop também tem alto potencial de redução das emissões de $\mathrm{CO}_{2}$ que pode chegar até $8 \%$ ou mais, mas a proporção de redução depende do ciclo de condução adotado, podendo gerar diferentes benefícios aos condutores. Com esta pesquisa conclui-se que o Start stop é uma importante tecnologia para produzir veículos mais eficientes e auxiliar na redução de poluição urbana por parte dos veículos, mas é necessário trabalhar no aperfeiçoamento do sistema a fim de melhorar as condições de conforto para os ocupantes aumentando sua aceitabilidade pelos consumidores.

\section{INTRODUÇÃO}

Atualmente os veículos automotivos são largamente utilizados pela sociedade, sendo um utilitário associado ao conforto e praticidade. Porém as frotas de veículos geram sérios problemas relacionados à poluição do ar. Pois os motores que equipam os veículos queimam, em sua maioria, combustível de origem fóssil como gasolina e diesel, emitindo para a atmosfera gases de efeito estufa tais como o dióxido de carbono $\left(\mathrm{CO}_{2}\right)$ e gases tóxicos a humanos e animais como o monóxido de carbono (CO), óxidos de nitrogênio (NOx), hidrocarboneto e material particulado [1] 
O problema da poluição tem se agravado com o aumento da frota de veículo nas últimas décadas, principalmente nos centros urbanos, como na cidade de São Paulo no Brasil. O alto nível de poluição e o uso excessivo de energia de origem fóssil motivaram as autoridades governamentais de vários países a investirem em pesquisa e desenvolvimento para reduzir as emissões de poluentes e o consumo de combustível fóssil por veículos automotivos [2] e [1].

A redução de emissões veiculares está atrelada à eficiência dos veículos, pois quanto menor a quantidade de combustível queimada menor deve ser a quantidade de gases emitida. Dessa forma o aumento da eficiência energética de veículos é uma meta de vários governos pelo mundo como uma alternativa para reduzir a poluição por veículos automotivos além de contribuir positivamente com o problema da escassez de uma fonte limitada de energia que é o petróleo.

Uma das ferramentas desenvolvidas pela indústria automotiva como resposta para melhorar a eficiência de seus veículos é um sistema automático de parada e partida do motor conhecido pelo termo inglês Start stop. Em linhas gerais este sistema desliga o motor quando o veículo fica parado em condições de trânsito e o religa quando o condutor aciona a embreagem ou acelerador, de forma automática, de modo a reduzir o consumo de combustível, que seria desperdiçado nos períodos de parada [3].

Este artigo tem como objetivo revisar os benefícios do sistema Start stop no consumo de combustível automotivo e emissões de dióxido de carbono $\left(\mathrm{CO}_{2}\right)$.

\section{REVISÃO DA LITERATURA}

A busca por veículos mais eficientes e menos poluidores foi e continua sendo incentivada por programas governamentais como o Programa de Controle da Poluição do Ar por Veículos Automotores (PROCONVE) criado em 1986 com o objetivo de regular a redução de emissões veiculares e promover o desenvolvimento tecnológico automotivo. O PROCONVE tem alcançados bons resultados e os veículos atuais emitem consideravelmente menos poluentes do que no período anterior à sua criação [2] e [4].

Mais recentemente, em 2012, foi lançado o Programa de Incentivo à Inovação Tecnológica e Adensamento da Cadeia Produtiva de Veículos Automotores (INOVAR-AUTO), que tem como princípio fornecer benefícios fiscais as empresas que invistam em pesquisa e desenvolvimento tecnológico aliado ao aumento de eficiência energética dos seus veículos [5].

O sistema Start stop é um sistema automático implementado nos veículos para desligar e religar o motor em períodos em que o veículo permanece parado no trânsito, com o objetivo de evitar o desperdício de combustível durante as paradas elevando a eficiência energética do veículo. A implementação deste sistema está sendo feita em vários veículos comercializados no Brasil com a finalidade de auxiliar as empresas a atingir metas de eficiência energética que o INOVAR-AUTO propôs [6].

Apesar de ter se popularizado há pouco tempo, o sistema Start stop não é uma tecnologia tão recente, sua ideia foi introduzida pela Toyota Crown no Japão na década de 70. Concepções semelhantes foram testadas em alguns modelos da Fiat e Volkswagen na década seguinte. Entretanto na época a tecnologia de injeção de combustível disponível dificultou a sua 
aceitação pelos consumidores por incômodos relacionados ao tempo necessário para o motor ser religado após a parada. Os sistemas de injeção eletrônica utilizados atualmente eliminam esse problema [7] e [8].

A inserção do Start stop nos veículos comercializados no Brasil foi realizada por meio de veículos importados e sofisticados, mas a busca por redução de consumo de combustível tem motivado a utilização desta tecnologia em vários outros veículos mais acessíveis. O primeiro veículo fabricado no Brasil com a tecnologia Start stop foi o Fiat Uno em 2014. Desde então vários outros modelos estão sendo contemplado com a tecnologia. Espera se que até o fim 2017 cerca de $70 \%$ dos veículos vendidos no Brasil possuam o sistema Start stop [9] e [10].

Na Europa o Start stop tem sido implantado mais rapidamente para auxiliar no cumprimento do limite de emissão de $\mathrm{CO}_{2}$. Segundo a Bosch em um trajeto de $7 \mathrm{~km}$ com doze paradas de 15 segundos cada, a ação do Start stop reduziria as emissões de $\mathrm{CO}_{2}$ em aproximadamente $8 \%$. Se as paradas demorarem mais tempo ou houver mais paradas este percentual pode ser bem maior [11].

\subsection{Componentes do sistema Start stop}

O sistema Start stop é constituído basicamente por nove componentes descritos a seguir, que podem ser observados na Figura 1. Na realidade alguns destes componentes não são restritos ao sistema Start stop, sendo necessários em qualquer veículo, contudo ao implementar o sistema é necessário observar algumas particularidades que estes componentes precisam atender para o Start Stop funcionar bem [7]:

1. Unidade de controle do motor: este componente gerencia o controle do motor, contém a programação de desligamento e religamento do motor e verifica as condições do motor de partida e alternador [8] e [7];

2. Unidade de vigilância da bateria: Monitora a carga da bateria, componente imprescindível para o Start Stop atuar [7];

3. Motor de partida reforçado: responsáveis por iniciar a rotação do motor até este entrar em funcionamento. Para veículos com o Start stop são usados motores mais robustos que os modelos convencionais [8].

4. Estabilizador de tensão: estabiliza a tensão elétrica de alimentação durante o período de acionamento do motor de partida [7].

5. Alternador: gerador de corrente alternada, acionado mecanicamente pelo motor, a corrente é retificada para alimentar o veículo. Os alternadores para o sistema Start stop devem ser mais eficientes que os alternadores convencionais [8].

6. Botão de acionamento do Start stop: permite ao condutor desligar o Start stop e ligá-lo quando desejar. Este botão é optativo estando presente em alguns veículos, mas não em todos. [7];

7. Gateway: atua na regulação e recuperação da bateria [7].

8. Sensor de ponto neutro: envia sinais elétricos para as possíveis condições de engrenamento. O Start stop só desliga o motor caso o veículo esteja em ponto morto, se houver marcha engrenada, o desligamento não é realizado [7].

9. Bateria (tecnologia AGM): baterias AGM (do inglês, Absobent Glass Mat) possuem maior capacidade de ciclos de carga e descarga, fornecendo energia 
ao veículo e ao sistema Start stop enquanto o motor está desligado, inclusive para religar o motor [8].

Figura 1: Representação dos componentes do sistema Start stop. Adaptada de [7]

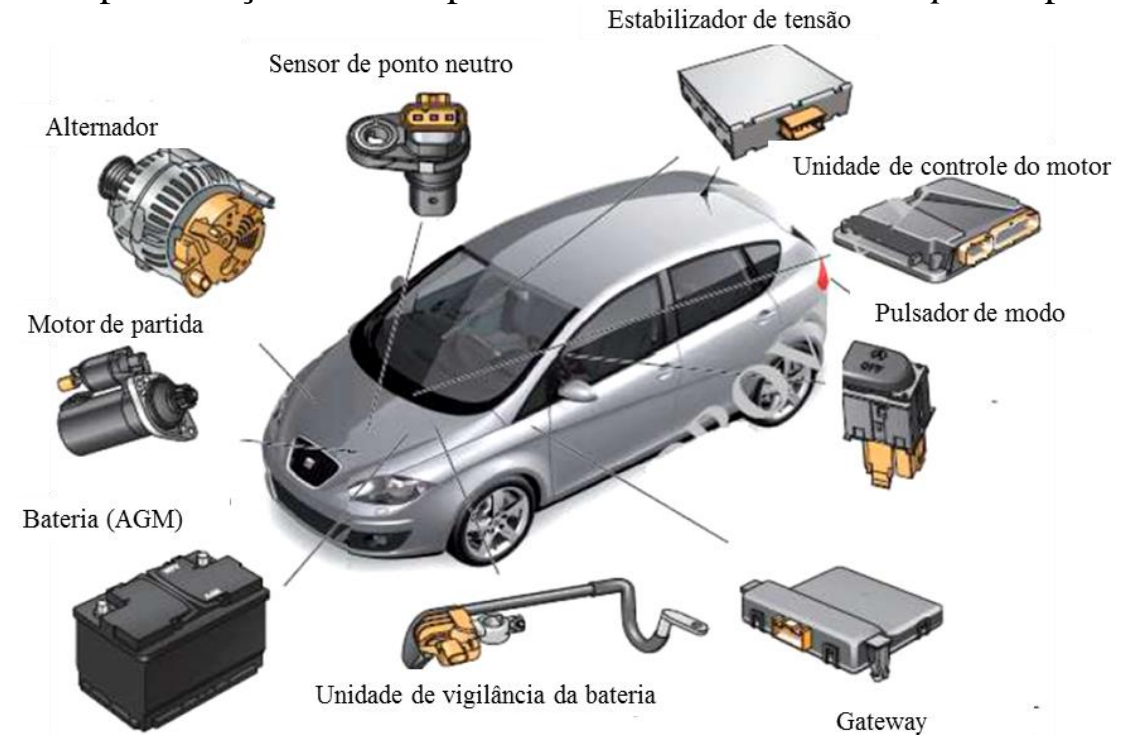

1.2. Condições de desligamento do motor

O Sistema atua de forma automática e sútil, uma programação estabelece condições para desligar e religar o motor, que são monitorados constantemente. Quando as condições são atendidas o sistema excuta o desligamento. Tais parâmetros são definidos na calibração do sistema na central de injeção, eles podem variar dependendo da marca ou modelo do veículo, mas alguns aspectos mais gerais são apresentados a seguir [12] e [6].

Para o Start stop desligar o motor é necessário que o sistema esteja ligado, o veículo esteja parado depois de ter se deslocado, a velocidade do motor deve ser baixa, estar em marcha lenta, o fluido de arrefecimento deve ter sua temperatura entre limites pré-estabelecido. A bateria deve estar carregada o suficiente para ligar o motor novamente, o habitáculo do veículo não deve necessitar de forte ação do arcondicionado, o condutor deve estar com o cinto travado, entre outros parâmetros que podem ser inseridos na calibração do sistema. Caso esses requisitos não sejam atendidos o sistema não efetua a parada do motor mesmo que o sistema esteja ligado [13].

1.3. Redução de consumo de combustível

O sistema apresenta várias vantagens, para os consumidores a principal é a economia de combustível, que pode chegar a $20 \%$ em cidades com tráfego de veículos intenso (real world), fora do ciclo de homologação. Para as empresas o sistema é uma forma de alcançar as metas de eficiência energética e de emissões de poluentes estabelecidas pela legislação. Para a sociedade de modo geral o benefício é a redução da poluição do ar e do uso de combustíveis fósseis pela frota de veículos atuais [6]. 
O efeito do Start stop depende do perfil de condução utilizado, pois a redução de consumo está relacionada com o tempo em que o veículo permanece parado, também denominado tempo de retardamento, que pode ser considerado o período em que o veículo permanece em marcha lenta. Portanto ao elevar o tempo de retardamento a redução de consumo é maior. $\mathrm{Na}$ realidade o tempo de retardamento pode ser alterado por vários fatores como rota, horário, dia, eventos, etc. Mas no ciclo de condução de homologação de veículos esse tempo é fixo, pois é utilizado como um padrão para medições e comparações, no Brasil é utilizado o ciclo norte americano FTP-75 para homologação de condução urbana. No FTP-75 o efeito do Start stop não tão expressivo em virtude do tempo de retardamento presente no ciclo, que é aproximadamente $19 \%$, porém existem outros ciclos não homologativos, mas que representam melhor o transito em regiões urbanas, como o ciclo de condução São Paulo, que representa melhor o trânsito na cidade de São Paulo e outras capitais brasileiras. No ciclo São Paulo o tempo de retardamento é aproximadamente $47 \%$. Obviamente o efeito do Start stop é bem maior no ciclo São Paulo, pois o tempo de retardamento é muito maior que no FTP-75, mostrando que quanto mais tempo um veículo permanece parado maior é o benefício do Start stop [14].

A redução de consumo pode ser interpretada como aumento da eficiência energética do veículo. Um exemplo disto é a redução do consumo energético alcançado recentemente com o modelo Novo Uno 2017 lançado pela Fiat no Brasil em 2016, a empresa inseriu no mercado uma versão do veículo $14 \%$ mais eficiente que a versão anterior. O veículo é um carro sub-compacto flex com motor 1.3, o veículo possui o sistema Start stop além de outras tecnologias que também tem o objetivo de aumentar a eficiência do veículo. Esta versão apresenta consumo energético de 1,58 $\mathrm{MJ} / \mathrm{km}$, enquanto a versão anterior tem o consumo de $1,84 \mathrm{MJ} / \mathrm{km}$. O consumo energético do veículo teve uma considerável redução, mostrando que as tecnologias inseridas no veículo, entre elas o Start stop cumprem seu objetivo de reduzir o consumo de combustível [15], [16] e [17].

\subsection{Redução das emissões de $\mathrm{CO}_{2}$}

O consumo de combustível está intimamente ligado à emissão de dióxido de carbono $\left(\mathrm{CO}_{2}\right)$, pois de acordo com a reação química de combustão em uma queima ideal (estequiométrica) todo o carbono presente no combustível deve ser convertido em $\mathrm{CO}_{2}$, todavia na realidade a combustão estequiométrica dificilmente ocorre, fazendo com que parte do carbono seja convertida em monóxido de carbono (CO) ou é liberado em forma de combustível não queimado. Estes compostos, apesar de nocivos, representam uma pequena parcela dos produtos da combustão, portanto é comum relacionar o consumo de um veículo às emissões de dióxido de carbono. $\mathrm{Na}$ Figura 2 pode ser observada a redução de emissões de $\mathrm{CO}_{2}$ de um veículo equipado com o sistema Start stop obtida por Fonseca, Casanova e Valés (2011), eles mediram as emissões de $\mathrm{CO}_{2}$ com o sistema Start stop ligado (10 MY-on), desligado (10 MYoff) e também fizeram testes com um veículo equivalente, mas sem o sistema Start stop $(9 M Y)$. Os testes foram realizados na Espanha em região urbana [18].

Fica claro com a Figura 2 que o veículo equipado com sistema Start stop ligado emite menos $\mathrm{CO}_{2}$ em relação ao veículo com sistema desligado e em relação a um veículo sem o sistema, a diferença está em torno de $12 \%$ entre os testes com o Start 
stop ligado e desligado. Observa-se também uma leve diferença entre os veículos sem Start Stop e com Start stop desligado, sendo que o veículo com Start stop emitiu menos $\mathrm{CO}_{2}$.

Figura 2: Emissões de $\mathrm{CO}_{2} \mathrm{x}$ velocidade. [18]

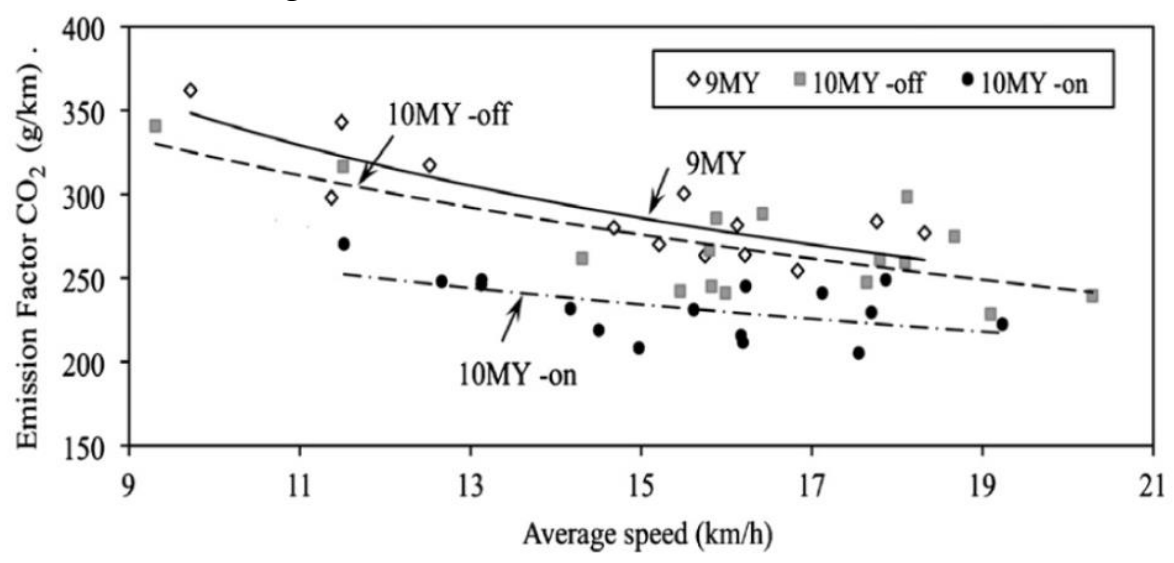

\subsection{Evoluções do Start stop}

Evoluções do sistema Start stop já estão sendo implementadas e podem ganhar mais visibilidade em um futuro próximo, como Start stop Avançado e o Start stop Coasting. O primeiro sistema desliga o motor antes do veículo está completamente parado, mas na iminência de parar, enquanto o segundo sistema é mais ousado, atuando em trechos que atualmente o Start stop convencional não contempla que é a condução em estrada, este sistema desliga o motor quando o veículo opera em altas velocidades, aproveitando a energia cinética para manter o movimento do veículo. $\mathrm{O}$ Start stop Avançado e Coasting podem propiciar maior efeito que os sistemas convencionais utilizados, os fornecedores defendem que o ganho pode chegar em torno de $25 \%$ ou mais, porém sua aplicação demanda estudos principalmente de segurança e aceitabilidade dos consumidores [8].

\subsection{Aspectos do Start stop que requerem melhorias}

Todavia algumas desvantagens são observadas com a implementação do Start stop. Como as exigências para funcionamento eficiente do Start stop, que requer um sistema de cargas robusto, pois a atuação do sistema demanda picos de energia, principalmente na partida do motor. A bateria precisa ter um nível de carga mínimo para religar o motor, caso contrário o desligamento não é permitido, de modo que é necessário um sistema que recarregue a bateria de forma eficiente. Essa tarefa cabe ao alternador, que é um gerador de corrente alternada, convertida em contínua para alimentar o veículo e recarregar a bateria, acionado mecanicamente pelo motor. Em outras palavras, para que de fato o sistema aumente à eficiência energética do veículo, o alternador, a bateria e os demais componentes do sistema de carga devem também trabalhar com alta eficiência, de forma que o aumento de eficiência que o Start stop proporciona não seja dissipado nos demais componentes necessários para o seu funcionamento. Porém, todos os componentes mais eficientes elevam os custos do produto, que é repassado aos consumidores [6] e [8]. 
Além de um sistema de cargas robusto existem outros pontos desfavoráveis, como possíveis incômodos para os ocupantes pelo desligamento de sistemas auxiliares, como ar-condicionado, rádio e GPS (do inglês Global Positioning System). Soluções para tais problemas continuam em desenvolvimento. No caso do ar-condicionado tenta-se evitar o desconforto térmico inserindo requisitos de temperatura interna do veículo na programação do sistema que impeça o desligamento do motor se a temperatura estiver acima do limite estabelecido pelo fabricante [19].

\section{DISCUSSÃO}

O sistema Start stop se apresenta como uma solução para reduzir o consumo de combustível e as emissões veiculares, porém o efeito na redução de consumo varia de acordo com o perfil de condução, ou seja, são sensíveis às rotas e horários. Nas regiões urbanas de maior tráfego o uso do sistema é altamente recomendado, pois seus efeitos são mais significativos que em trechos de estrada e rodovias.

Os benefícios do Start stop são notórios quando se considera um ciclo de condução em cidades com muito trânsito ou congestionamento, como representado pelo ciclo São Paulo. Os principais benefícios que a implementação do Start stop trás é a redução de consumo de combustível e das emissões de $\mathrm{CO}_{2}$ como pode ser observado na Figura 2, onde são apresentados os resultados obtidos por Fonseca, Casanova e Valés [18], indicando que o veículo com sistema Start stop ligado emite $12 \%$ menos $\mathrm{CO}_{2}$. Também nota-se que mesmo com o sistema desligado o veículo que possui Start stop emite menos $\mathrm{CO}_{2}$ do que um veículo equivalente sem o sistema Start stop. Esse resultado pode ser consequência da eficiência dos componentes do sistema de carga como alternador e bateria, que o sistema Start stop geralmente exige que sejam mais robustos e eficientes. Entretanto como a diferença é pequena e a dispersão dos dados observados é alta é difícil afirmar que veículos equivalentes com e sem o sistema Start Stop apresentem emissão de $\mathrm{CO}_{2}$ significativamente diferentes quando o Start Stop está desligado, apenas observa-se a tendência que as emissões do veículo com Start Stop, mesmo desligado, são menores, que pode ou não está relacionado ao fato dos demais componentes serem mais eficientes para implementação do Start stop, que nos veículos sem o sistema.

O Start stop ainda pode gerar desconforto aos ocupantes, em razão das condições que desligam o veículo e interrompem o funcionamento de sistemas auxiliares. Porém essa é uma questão relativa, algumas funções auxiliares são mais significativas para algumas pessoas do que outras, tornando o melhoramento do sistema também subjetivo, pois é inviável aplicar várias restrições, porque impossibilitaria um funcionamento eficiente. Dessa forma é necessário um estudo mais aprofundado acerca dos parâmetros de conforto para atender ao máximo possível as solicitações dos consumidores sem perder desempenho do sistema Start Stop. Uma possibilidade para atender as exigências do consumidor é permitir ao consumidor optar pelas funções auxiliares que lhe são mais importantes, de forma que satisfaça a uma maior gama de públicos alvos e torne o sistema mais popular entre os consumidores.

Sobre o aumento do preço devido à implementação do Start Stop junto com todos os equipamentos necessários para o seu bom funcionamento discute-se sobre duas perspectivas a serem observadas. A primeira é que é responsabilidade da indústria automotiva atender os limites de emissões e tornar seus veículos mais eficientes de forma competitiva, pois um produto extremamente caro não deve ter boa aceitabilidade dos consumidores, portanto por 
uma questão de competitividade as empresas devem buscar veículos com alto desempenho atendendo as regulamentações. Tendo o volume de produção uma oportunidade de baratear o sistema.

Em uma segunda perspectiva, o problema da poluição é também de responsabilidade das autoridades públicas legais, portanto o governo deve estabelecer normas e leis que regulamentem limites de emissões, ao mesmo tempo deve fiscalizar, mas também auxiliar o setor a conseguir meios para alcançar metas restritivas de emissões, além do trabalho de conscientização da sociedade sobre a importância da eficiência energética e do consumo consciente de energia e derivados do petróleo. No Brasil o Governo oferece vantagens fiscais às empresas do ramo automotivo que investem no desenvolvimento tecnológico para elevar a eficiência energética dos veículos por meio do programa INOVAR-AUTO.

A sociedade por sua vez deve também compreender a importância em adquiri automóveis mais econômicos e que pagar um pouco mais caro por um veículo mais eficiente com tecnologias que reduzam os danos ao ambiente é vantajoso e necessário para preservar a qualidade do ar e do meio ambiente. No caso do Start stop o consumidor que paga por este sistema tem a vantagem de ainda economizar com combustível, que é um ponto bastante positivo.

Sobre as evoluções do sistema Start Stop deve se salientar que os sistemas Start Stop Avançado e o Start Stop Coasting necessitam de contínuos estudos, uma vez que há maior risco de rejeição dos consumidores. No caso do Start stop Avançado uma possível rejeição pelos clientes pode surgir devido o desligamento de sistemas auxiliares com mais frequência, uma vez que o período de funcionamento do Start stop deve aumentar.

No caso do Coasting outro ponto merece atenção, pois o desligamento do motor pode comprometer a capacidade de resposta do condutor em uma situação de perigo, principalmente considerando que este tipo de tecnologia é direcionado para condução em altas velocidades, que é característico de condução em estrada, em que é importante ter mais sensibilidade de resposta dos sistemas de freios e do veículo como um todo na iminência de acidentes. Como em muitos veículos os sistemas de freios são hidráulicos que necessitam da ação do motor, com o seu desligamento pode-se perder a capacidade de frear o véiculo aumentando mais os riscos de acidentes. Considerando ainda o contexto brasileiro, em que a qualidade das rodovias em muitos trechos não é boa, o risco de acidentes devido ao retardo na resposta do veículo é ainda mais preocupante.

\section{CONCLUSÕES}

Este artigo apresentou uma revisão literária sobre os benefícios do sistema Start stop no consumo de combustível e emissões de $\mathrm{CO}_{2}$ em veículos automotivos. Com os resultados é possível concluir que:

1. O Start Stop tem como maior beneficio alto potencial de redução do consumo de combustível e de emissões de $\mathrm{CO}_{2}$ em ciclo de condução real em área urbana com tráfego intenso, mas que algumas desvantagens ainda precisam ser trabalhadas pelos fornecedores do sistema e de veículos; 
2. O Start stop trás como benefício às empresas uma forma de alcançar as metas de eficiência energéticas propostas pelo Governo; Ao reduzir o consumo de combustível, o consumidor tem a vantagem da economia com redução de abastecimento de combustível; e obviamente a sociedade tem como maior benefício à redução da poluição oriunda dos veículos nas áreas urbanas;

3. Mas a redução de consumo e emissões de $\mathrm{CO}_{2}$ depende do padrão de condução, não sendo possível afirmar a quantidade de combustível economizada, pois isso varia com o perfil de condução, que se alteram durante um mesmo dia em um mesmo trecho. Como a cada ano tem-se intensificado o trânsito e congestionamento nas capitais brasileiras, como São Paulo, por exemplo, o Start stop pode ser um forte aliado na redução de consumo de combustível e da poluição urbana ( emissão de $\mathrm{CO}_{2}$ ) oriunda da frota automotiva;

4. Apesar dos benefícios que o sistema Start stop propicia existem também desvantagens, portanto é necessário um melhoramento do sistema a fim de tornar seu funcionamento mais cômodo para os clientes. No caso do conforto térmico, o problema do desligamento do ar-condicionado poderia ser solucionado com o uso de compressor elétrico. Isso representaria uma carga para o sistema de cargas do veículo, mas aumentaria a aceitabilidade por parte dos consumidores com relação ao funcionamento do ar-condicionado.

Para trabalhos futuros recomenda-se um estudo experimental da influência do sistema Start stop em veículos com boa representatividade no Brasil em ciclos de condução mais próximos da realidade brasileira.

\section{AGRADECIMENTOS}

Os autores agradecem à Fiat Chrysler Automobiles - FCA pelo apoio financeiro e por incentivar o desenvolvimento tecnológico automotivo no Brasil por meio do PROGRAMA INOVAR FCA - UNIVERSIDADES - RESIDÊNCIA TECNOLÓGICA PARA ENGENHEIROS.

\section{REFERÊNCIAS}

[1] Vicentini, Pedro Caffaro. Uso de modelos de qualidade do ar para a avaliação do efeito do PROCONVE entre 2008 e 2010 na região metropolitana do Rio de Janeiro. Rio de Janeiro: Tese de Doutorado em Engenharia Mecânica da Universidade Federal do Rio de Janeiro, 2011.

[2] CONAMA, Conselho Nacional do Meio Ambiente. Resolução. N. 18 de Maio de 1986, 1986.

[3] Almeida, T., Soares, S. e Reis, M. N. E. Fracionamento de Coast Down de veículos automotores. Campina Grande: VI Congresso Nacional de Engenharia Mecânica - CONEM, 2010.

[4] Mendes, Francisco Eduardo. Avaliação de Programas de controle de poluição atmosférica por veículos leves no Brasil. Rio de Janeiro: Tese de Doutorado em Ciências em Planejamento energético da Universidade Federal do Rio de Janeiro, 2004.

[5] Brasil. Lei n. ${ }^{\circ}$ 12.715, de 7 de setembro de 2012, Institui o Programa de Incentivo à Inovação Tecnológica e Adensamento da Cadeia Produtiva de Veículos Automotores, 2012. 
[6] VERMIASSI, William. Análise do sistema Stop/start do motor. São Caetano do Sul: Monografia de especialização em engenharia automotiva do Instituto Mauá de Tecnologia, 2012.

[7] Marques, Carlos Filipe de Freitas. Estudo e análise do sistema de arranque e paragem automática do motor no automóvel. Porto: Dissertação de mestrado em Engenharia mecânica da Universidade de Porto, 2009.

[8] SILVA, Marcela Carvalho Conegero da. O impacto ambiental na redução do consumo de combustível e emissão de poluentes do sistema start stop. Monografia de especialização em engenharia automotiva - Instituto Mauá de Tecnologia: São Caetano do Sul, 2013.

[9] CRERWONKA, M. Novo UNO é o primeiro carro nacional com Start-Stop. Portal do Trânsito. Disponível em < http://portaldotransito.com.br/noticias/novo-uno-e-o-primeirocarro-nacional-com-start-stop/ > acesso em 20/05/2017 as 10:21, 2014.

[10] Rodrigues, H. Start-Stop estará em 70\% dos carros novos em 2017. Autos segredos. Disponível em <https://www.autossegredos.com.br/segredos/start-stop-estara-em-70-doscarros-novos-em-2017/> acesso em 21/05/2017 às 17:39, 2014.

[11] BOSCH. O novo sistema Start/Stop da Bosch reduz o consumo de combustível e as emissões de $\mathrm{CO2}$ com eficiência. Disponível em <http://www.brasil.bosch.com.br/pt/br/br_main/newsroom_1/topics_1/start_stop_system/siste ma_start_stop_1.html> Acesso em 21;05/2017 às 9:23, 2017.

[12] SILVA, Adriano Rodrigues da, et al., et al. Sistema Start/Stop. V Simpósio Nacional de Ciências e Meio Ambiente - UniEvanvélica, 2014.

[13] SEAT. Sistema Star stop.

[14] IEMA, Instituto de Energia e Meio Ambiente. Comentários e recomendações sobre créditos Off-cycle propostos pela portaria MDIC n 74/2015. 2015.

[15] Fiat. Uno 2017. Site Fiat, Disponível em <http://www.fiat.com.br/carros/uno.html> acesso em 04/04/2017 às 09:58, 2017.

[16] PBE. Programa Brasileiro de Etiquetagem. Consulta de veículos leves. Disponível em $<$ http://pbeveicular.petrobras.com.br/TabelaConsumo.aspx> acesso em 03/04/2017 ás 15:03, 2017.

[17] VIDAL, Marlos Ney. Economia de combustível vai muito além da evolução do motor. Site Autos Segredo. Disponível em <http://www.autossegredos.com.br/mercado/materias-especiais/economia-de-combustivelvai-muito-alem-da-evolucao-do-motor/>, em 22/03/2017 às 10:23, 2017.

[18] FONSECA, Natália, Casanova, J. e Valés, M. Influence of the stop/start system on CO2 emission of a diesel vehicle in urban traffic. Transportation Research Part D, n. 16, p. 194-200, 2011.

[19] TECH, Eure. Sisteam Star stop. 2012. 